\title{
Improving Loss Minimization in 33kv Power Distribution Network Using Optimized Genetic Algorithm
}

\author{
Ngang Bassey Ngang, Bakare Kazeem, Ugwu Kevin Ikechukwu, Aneke Nnamere Ezekiel \\ Department of Electrical and Electronic Engineering, Faculty of Engineering, Enugu State University of Science and Technology (ESUT), \\ Enugu, Nigeria
}

Email address:

nbngang@gmail.com (N. B. Ngang)

\section{To cite this article:}

Ngang Bassey Ngang, Bakare Kazeem, Ugwu Kevin Ikechukwu, Aneke Nnamere Ezekiel. Improving Loss Minimization in 33kv Power Distribution Network Using Optimized Genetic Algorithm. International Journal of Systems Engineering. Vol. 5, No. 1, 2021 , pp. $34-42$. doi: $10.11648 /$ j.ijse.20210501.15

Received: May 3, 2021; Accepted: May 26, 2021; Published: June 9, 2021

\begin{abstract}
The epileptic power supply from the national grid due to instability is a concern to energy consumer. This instability in power supply experienced in power distribution network could be minimized by introducing Optimized Genetic Algorithm (OGA). It is achieved by characterizing 33KV distribution network, running the load flow of the characterized $33 \mathrm{KV}$ distribution network, determining the distribution losses from the load flow. Minimizing the determined losses in $33 \mathrm{kv}$ distribution network using (OGA), and designing SIMULINK model for improving loss minimization in $33 \mathrm{kv}$ power distribution network using OGA. Finally, validating and justifying the percentage of loss reduction in improving loss minimization in $33 \mathrm{kv}$ power distribution network without and with OGA. The results obtained are conventional percentage power loss in $33 \mathrm{KV}$ distribution network, $75 \%$, while that when OGA is incorporated in the system is $72.9 \%$. With these results obtained, the percentage improvement in loss reduction in $33 \mathrm{KV}$ distribution network when OGA is used is $2.1 \%$. The conventional percentage of power loss in $33 \mathrm{KV}$ distribution network is $80 \%$. The percentage power loss in the distribution network now is $72.9 \%$; hence, power loss reduction in distribution network. Unmitigated power loss was $76.7 \%$ when OGA is introduced we had $74.63 \%$. The percentage power loss in distribution network in bus 8 is $81.7 \%$ while that when OGA is applied is $79.49 \%$. The percentage power loss in bus 9 of $33 \mathrm{KV}$ distribution network is $86.7 \%$. Finally, when optimized genetic algorithm is incorporated in the system the percentage power loss in the network was reduced to $84.36 \%$.
\end{abstract}

Keywords: Improving, Loss Minimization, Power Distribution, Optimized, Genetic Algorithm (OGA)

\section{Introduction}

Electricity consumers are increasing their demand for quality power supply more than what we had three years ago. It requires a modern technique to contain the situation. The growth of electricity demand is increasing rapidly which will require techniques or methods to enhance loss reduction in the distribution network. Many authors have proposed many types of ways to achieve a considerable reduction in power losses causing power outages. A closer review of known methods will be considered in the subheading below to see which of the techniques could reduce system energy loss and alleviates distribution congestion, as well as improving voltage profile a good method should be able to enhance reliability and provides lower operating cost. Distribution means the electric power from transmission being distributed to the final consumers in a safe and reliable manner.

\subsection{Aim of the Study}

This paper is aimed at using Optimized Genetic Algorithm (OGA) to improve loss minimization in $33 \mathrm{kV}$ Power Distribution Network in southern Nigeria.

\subsection{Objectives}

Frequent tripping of feeders and protective devices resulting in power failure as well power losses from copper conductors had become an endemic problem, therefore, the objective of this research work was to

i. Collect data from the characterized $33 \mathrm{Kv}$ line from Abakaliki to Ugep.

ii. Use the line parameters to run the load flow of the 
characterized $33 \mathrm{kV}$ distribution Network in order determine the distribution losses.

iii. Minimize the determined losses in $33 \mathrm{kV}$ short transmission line $(50 \mathrm{kM})$.

iv. Design a SIMULINK model for improving loss minimization in $33 \mathrm{kV}$ power distribution network using Optimized Genetic Algorithm (OGA).

$\mathrm{v}$. Validate in order to justify the percentage of loss reduction in improving loss minimization $33 \mathrm{kV}$ power distribution network without and with Optimized Genetic Algorithm (OGA)

\section{Extent of Past Related Works}

In a distribution network there is usually negative impact when Distributed generators tied to the system are wrongly placed. They can cause system surge due to reflection of mismatched impedance (Characteristic impedance). The resultant effect could lead to low power quality and reliability levels, the voltage regulation would not be effective as well $[1,2]$. The sizing and placement of DG's are determined from the optimization algorithms, which are read an analysed in the literature reviewed from different angles as in the study of $[3,4]$ where the Kalman filter algorithm was used to reduce power losses. The authors in previous study [5] proposed a probabilistic power flow technique with embedded Genetic Algorithm to determine the problem of the total costs reduction. In that technique, the costs that has to do with the installation of DGs in a distribution system are made up of operating cost, running and investment costs. The method of Optimized Genetic Algorithm has been widely adopted to reduce transmission losses as it is simple and user friendly [6]. Local particle swarm optimization (PSO) is another useful technique but lacks the numerical accuracy since it is a population-based stochastic optimization technique [7]. We also have optimization algorithms for multi-objective as a technique which was proposed as well as pareto-front [8]. In [9], the authors talked about the use of an advanced Pareto-front non-dominated sorting multi-objective particle swarm optimization technique. The optimization problem considered two multi-objective functions; the constraints were the power loss reduction, voltage stability improvements with voltage profile and the power balance. The multi-objective performance index was discussed [10] to improve the voltage profile and minimise the system losses. In this work [11], the criss cross optimal algorithm and Monte Carlo simulation was equally presented as the desired tool to reduce the total costs and power losses. While the work by [12], the authors proposed an improved particle swarm optimization (IPSO) algorithm for reducing, electricity price, running cost and network loss. The authors [13] recommended improved analytical method to determine the optimal size of about four different DG typologies by utilizing an effective methodology. While in the study,[14], the optimum sizes and locations of DG units were determined selecting the power losses and voltage profile as objective functions. Shunt capacitors (SCs) are not exceptions as they could be used to minimize the variability of some DGs from a reliable energy source. Adoption of Genetic Algorithm (GA) was used in the placement and sizing to improve the bus voltage magnitude and minimize power losses as was described and implemented in the ETAP software [15]. In the review [16], a Sequential quadratic programming-based algorithm combined with Genetic Algorithm was proposed for mitigating the costs, power losses and network upgrading. A load concentration factorbased on analytical technique was presented to determine the optimal solution for power loss reduction and improvement in the voltage profile [17]. In this work, a relevant technique for reducing transmission losses in a $33 \mathrm{kV}$ distribution network explained in details the feasibility of the method. This proposed technique/method is developed on the Optimized Genetic Algorithm (OGA) to solve the endemic problem. The main original contributions of this work depended on the ability of the technique to deal with DGs to regulate the reactive power introduced in the network by solving the Optimal power factor (PF) of DGs while taking into consideration the contribution of the SCs and other limitations on the initial maximum installed capacity of the Synchronous Generators.

\section{Methodology}

The collection of required data for analysis and determination of losses was the first step. It is done in this manner, characterizing $33 \mathrm{KV}$ distribution network, running the load flow of the characterized $33 \mathrm{KV}$ distribution network, determining the distribution losses from the load flow. Minimizing the determined losses in $33 \mathrm{kv}$ distribution network using optimized genetic algorithms, and designing SIMULINK model for improving loss minimization in $33 \mathrm{kv}$ power distribution network using optimized genetic algorithm. Finally, validating and justifying the percentage of loss reduction in improving loss minimization in $33 \mathrm{kv}$ power distribution network without and with optimized genetic algorithm.

\subsection{Characterization of the $33 \mathrm{kV}$ Distribution System}

Table 1. Data from 33kv substation Abakaliki-Ugep.

\begin{tabular}{llllll}
\hline $\begin{array}{l}\text { Bus } \\
\text { No }\end{array}$ & $\begin{array}{l}\text { P.u.volts } \\
\text { Voltage }\end{array}$ & $\begin{array}{l}\text { Load } \\
\text { (MW) }\end{array}$ & $\begin{array}{l}\text { Load } \\
\text { (MVAR) }\end{array}$ & $\begin{array}{l}\text { Gen } \\
\text { (MW) }\end{array}$ & $\begin{array}{l}\text { Gen } \\
\text { (MVAR) }\end{array}$ \\
\hline 1 & 1.04 & 00.0 & 0.0 & 0.0 & 0.0 \\
2 & 1.0 & 00.0 & 0.0 & 0.0 & 0.0 \\
3 & 1.0 & 150.0 & 120.0 & 0.0 & 0.0 \\
4 & 1.0 & 0.0 & 0.0 & 0.0 & 0.0 \\
5 & 1.0 & 120.0 & 60.0 & 0.0 & 0.0 \\
6 & 1.0 & 140.0 & 90.0 & 0.0 & 0.0 \\
7 & 1.0 & 0.0 & 0.0 & 0.0 & 0.0 \\
8 & 1.0 & 110.0 & 90.0 & 0.0 & 0.0 \\
9 & 1.0 & 80.0 & 50 & 0.0 & 0.0 \\
10 & 1.035 & 0.0 & 0.0 & 200.0 & 0.0 \\
11 & 1.03 & 0.0 & 0.0 & 160.0 & 0.0 \\
\hline
\end{tabular}




\subsection{To Run the Load Flow of the Characterized 33KV Distribution Network}

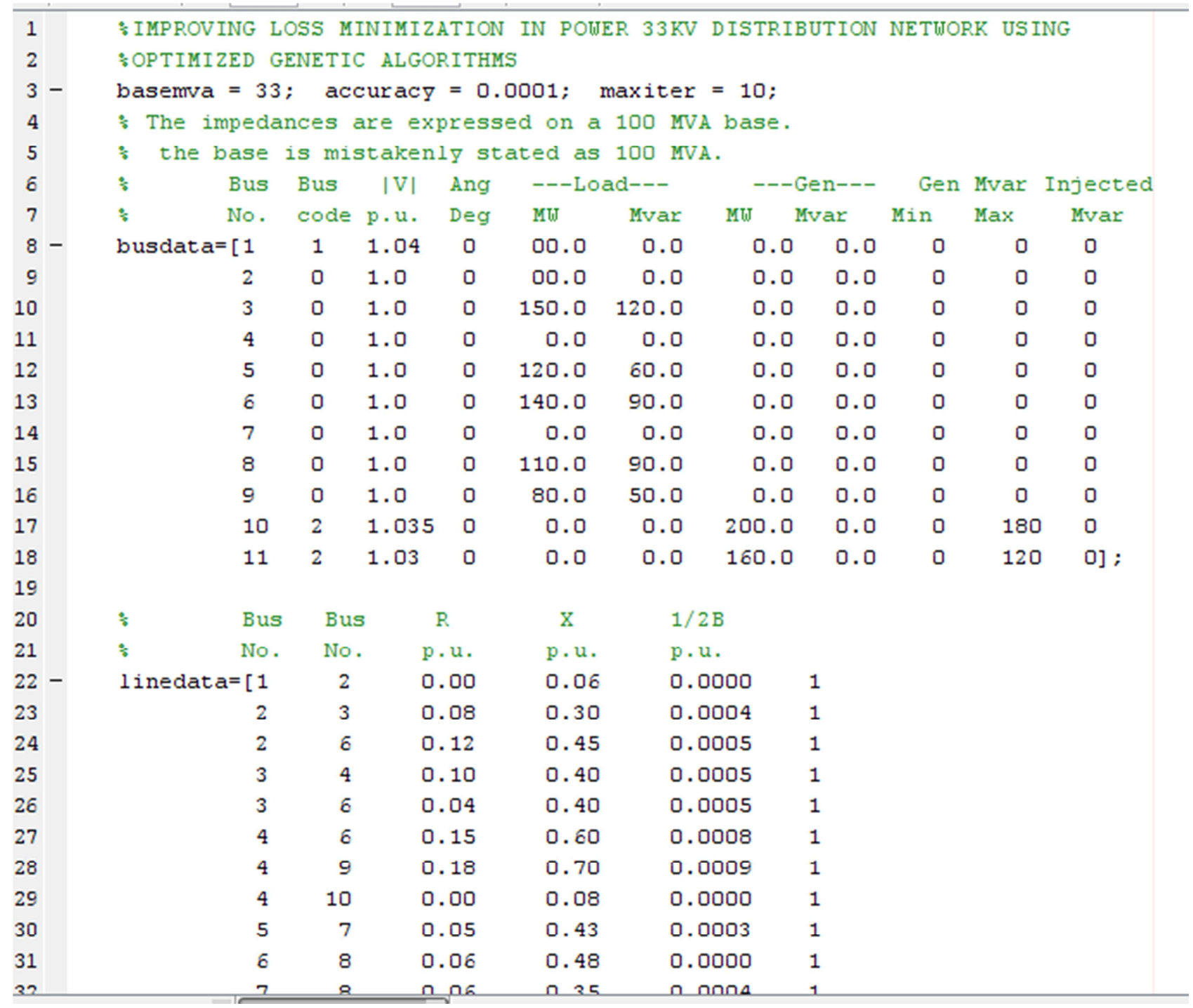

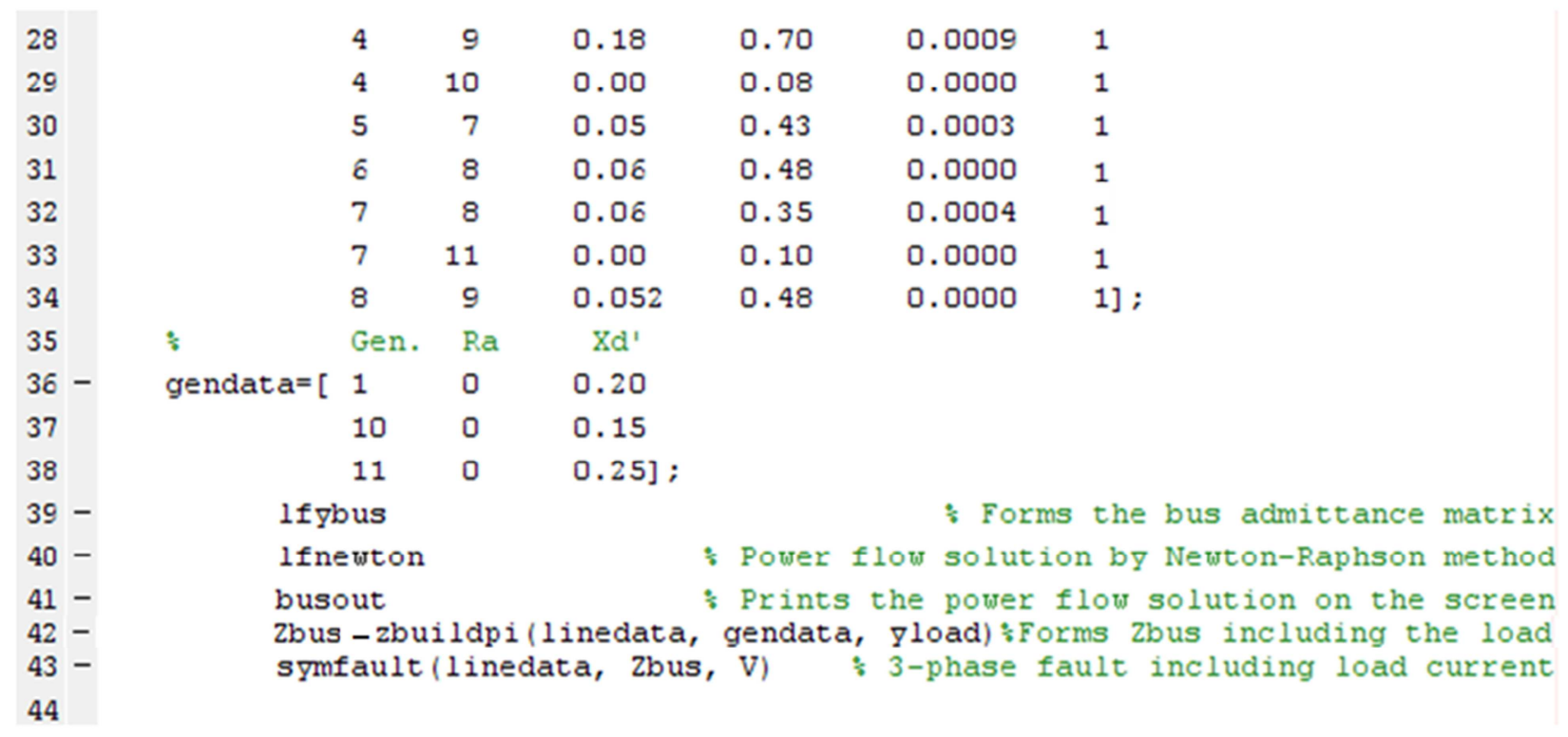

Figure 1. Load flow analysis of the $33 \mathrm{kV}$ distribution network. 


\subsubsection{Improving Loss Minimization in Power $33 \mathrm{kv}$ Distribution Network Using \% Optimized Genetic Algorithms}

basemva $=33$; accuracy $=0.0001 ;$ maxiter $=10$;

$\%$ The impedances are expressed on a 100 MVA base.

$\%$ the base is mistakenly stated as 100 MVA.

$\% \quad$ Bus Bus $|\mathrm{V}|$ Ang ---Load--- ---Gen--- Gen Mvar Injected

\% No. codep.u. Deg MW Mvar MW Mvar Min Max Mvar busdata $=\left[\begin{array}{lllllllllll}1 & 1 & 1.04 & 0 & 00.0 & 0.0 & 0.0 & 0.0 & 0 & 0 & 0\end{array}\right.$

$\begin{array}{lllllllllll}2 & 0 & 1.0 & 0 & 00.0 & 0.0 & 0.0 & 0.0 & 0 & 0 & 0\end{array}$

$\begin{array}{llllllllllll}3 & 0 & 1.0 & 0 & 150.0 & 120.0 & 0.0 & 0.0 & 0 & 0 & 0\end{array}$

$\begin{array}{lllllllllll}4 & 0 & 1.0 & 0 & 0.0 & 0.0 & 0.0 & 0.0 & 0 & 0 & 0\end{array}$

$\begin{array}{lllllllllll}5 & 0 & 1.0 & 0 & 120.0 & 60.0 & 0.0 & 0.0 & 0 & 0 & 0\end{array}$

$\begin{array}{llllllllllll}6 & 0 & 1.0 & 0 & 140.0 & 90.0 & 0.0 & 0.0 & 0 & 0 & 0\end{array}$

$\begin{array}{lllllllllll}7 & 0 & 1.0 & 0 & 0.0 & 0.0 & 0.0 & 0.0 & 0 & 0 & 0\end{array}$

$\begin{array}{lllllllllll}8 & 0 & 1.0 & 0 & 110.0 & 90.0 & 0.0 & 0.0 & 0 & 0 & 0\end{array}$

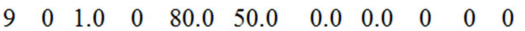

$\begin{array}{lllllllllll}10 & 2 & 1.035 & 0 & 0.0 & 0.0 & 200.0 & 0.0 & 0 & 180 & 0\end{array}$

$\left.\begin{array}{lllllllllll}11 & 2 & 1.03 & 0 & 0.0 & 0.0 & 160.0 & 0.0 & 0 & 120 & 0\end{array}\right]$;

$\%$ Bus Bus R $\mathrm{X} \quad 1 / 2 \mathrm{~B}$

$\%$ No. No. p.u. p.u. p.u.

linedata $=\left[\begin{array}{llllll}1 & 2 & 0.00 & 0.06 & 0.0000 & 1\end{array}\right.$

$\begin{array}{llllll}2 & 3 & 0.08 & 0.30 & 0.0004 & 1\end{array}$

$\begin{array}{llllll}2 & 6 & 0.12 & 0.45 & 0.0005 & 1\end{array}$

$\begin{array}{llllll}3 & 4 & 0.10 & 0.40 & 0.0005 & 1\end{array}$

$\begin{array}{llllll}3 & 6 & 0.04 & 0.40 & 0.0005 & 1\end{array}$

$\begin{array}{lllllll}4 & 6 & 0.15 & 0.60 & 0.0008 & 1\end{array}$

$\begin{array}{llllll}4 & 9 & 0.18 & 0.70 & 0.0009 & 1\end{array}$

$\begin{array}{llllll}4 & 10 & 0.00 & 0.08 & 0.0000 & 1\end{array}$

$\begin{array}{llllll}5 & 7 & 0.05 & 0.43 & 0.0003 & 1\end{array}$

$\begin{array}{llllll}6 & 8 & 0.06 & 0.48 & 0.0000 & 1\end{array}$

$\begin{array}{lllllll}7 & 8 & 0.06 & 0.35 & 0.0004 & 1\end{array}$

$\begin{array}{llllll}7 & 11 & 0.00 & 0.10 & 0.0000 & 1\end{array}$

$\left.\begin{array}{llllll}8 & 9 & 0.052 & 0.48 & 0.0000 & 1\end{array}\right] ;$

$\% \quad$ Gen. $\mathrm{Ra} \quad \mathrm{Xd}$

gendata $=\left[\begin{array}{lll}1 & 0 & 0.20\end{array}\right.$

$\begin{array}{lll}10 & 0 & 0.15\end{array}$

$\left.\begin{array}{lll}11 & 0 & 0.25\end{array}\right]$;

lfybus

lfnewton $\quad \%$ Power flow solution by Newton-Raphson method

busout $\quad \%$ Prints the power flow solution on the screen

Zbus=zbuildpi(linedata, gendata, yload)\%Forms Zbus including the load

symfault(linedata, Zbus, V) \% 3-phase fault including load current

\subsubsection{Power Flow Solution by Newton-Raphson Method} Maximum Power Mismatch=2.83789e-007 No. of Iterations $=10$

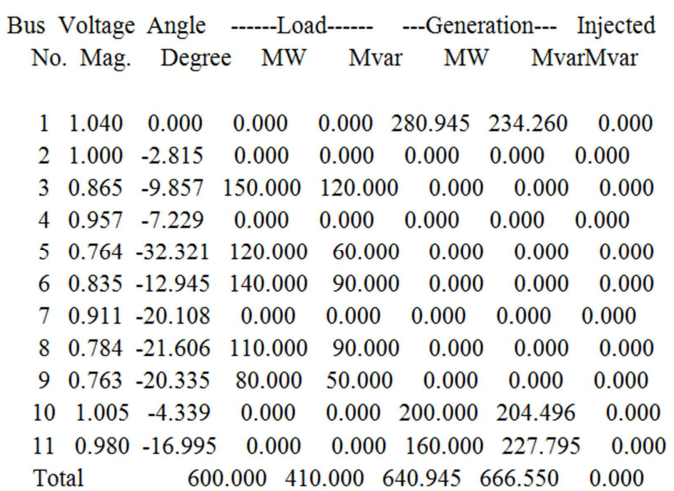

The total power is $600 \mathrm{MW}$. On the other hand the faulty buses are bus 3, 5, 68 and 9 because their P.u.volts did not fall within 0.95 to 1.05 p.u. Volt. Their respective power losses are 150MW, 120MW, 140MW, 110MW and 80MW.

\subsection{To determine the Distribution Losses from the Load Flow}

Table 2. Showing determined distribution losses.

\begin{tabular}{|c|c|c|}
\hline $\begin{array}{l}\text { No of } \\
\text { Loss } \\
\text { Buses }\end{array}$ & $\begin{array}{l}\text { P.u.volts That Atributes to the } \\
\text { Power Losses in the } \\
\text { Distribution Network }\end{array}$ & $\begin{array}{l}\text { Distributed Power } \\
\text { Losses (MW) in These } \\
\text { Buses }\end{array}$ \\
\hline 3 & 0.865 & 150 \\
\hline 5 & 0.76 & 120 \\
\hline 6 & 0.835 & 140 \\
\hline 8 & 0.784 & 110 \\
\hline 9 & 0.763 & 80 \\
\hline
\end{tabular}

Total power $600 \mathrm{MW}$

Then, applying formula to find power loss in the buses

$$
\mathrm{PLR}_{\mathrm{bus}}=\frac{\mathrm{P}_{\mathrm{bus}}-\mathrm{PL}_{\mathrm{bus}}^{\mathrm{final}}}{\mathrm{P}_{\mathrm{bus}}} \times \frac{100}{1}
$$

Where

$\mathrm{PLR}_{\text {bus }}$ is percentage of power loss in a given bus in distribution network

$\mathrm{P}_{\text {bus }}$ is total power in the distribution network bus

$\underline{\mathrm{PL}}_{\text {bus }}{ }^{\text {final }}$ is power loss in the bus of distribution network

To find power loss in bus 3 of distribution network

$$
\begin{aligned}
& \mathrm{PLR}_{3}=\frac{\mathrm{P}-\mathrm{PL}_{3}^{\text {final }}}{\mathrm{P}} \times \frac{100}{1} \\
& \mathrm{PLR}_{3}=\frac{600-150}{600} \times \frac{100}{1}
\end{aligned}
$$

$\mathrm{PLR}_{3}=75 \%$

To determine power loss in bus 5

$$
\begin{aligned}
& \mathrm{PLR}_{5}=\frac{\mathrm{P}-\mathrm{PL}_{5}^{\text {final }}}{\mathrm{P}} \times \frac{100}{1} \\
& \mathrm{PLR}_{5}=\frac{600-120}{600} \times \frac{100}{1}
\end{aligned}
$$

$\mathrm{PLR}_{5}=80 \%$

To determine power loss in bus 6

$$
\begin{aligned}
& \mathrm{PLR}_{6}=\frac{\mathrm{P}-\mathrm{PL}_{6}^{\text {final }}}{\mathrm{P}} \times \frac{100}{1} \\
& \mathrm{PLR}_{6}=\frac{600-140}{600} \times \frac{100}{1}
\end{aligned}
$$

$\mathrm{PLR}_{6}=76.7 \%$

To determine power loss in bus 6

$$
\begin{aligned}
& \mathrm{PLR}_{6}=\frac{\mathrm{P}-\mathrm{PL}_{6}^{\text {final }}}{\mathrm{P}} \times \frac{100}{1} \\
& \mathrm{PLR}_{6}=\frac{600-80}{600} \times \frac{100}{1}
\end{aligned}
$$

$\mathrm{PLR}_{6}=76.7 \%$

To determine power loss in bus 8

$$
\mathrm{PLR}_{8}=\frac{\mathrm{P}-\mathrm{PL}_{8}^{\text {final }}}{\mathrm{P}} \times \frac{100}{1}
$$




$$
\mathrm{PLR}_{8}=\frac{600-110}{600} \times \frac{100}{1}
$$

$\mathrm{PLR}_{8}=81.7 \%$

To determine power loss in bus 9

$$
\begin{aligned}
& \mathrm{PLR}_{9}=\frac{\mathrm{P}-\mathrm{PL}_{9}^{\text {final }}}{\mathrm{P}} \times \frac{100}{1} \\
& \mathrm{PLR}_{9}=\frac{600-80}{600} \times \frac{100}{1}
\end{aligned}
$$

$\mathrm{PLR}_{9}=86.7 \%$

\subsection{To minimize the Determined Losses in $33 \mathrm{kv}$ Distribution Network Using Optimized Genetic Algorithms}

Minimize

$$
\mathrm{P}=3 \mathrm{X} 1+0.865 \mathrm{X} 2+150 \mathrm{X} 3
$$

ST.

$$
\begin{gathered}
5 \times 1+0.76 \times 2+120 \times 3 \leq 80 \\
6 \times 1+0.835 \times 2+140 \times 3 \leq 76.7 \\
8 X 1+0.784 \times 2+110 \times 3 \leq 81.7 \\
9 \times 1+0.763 \times 2+80 \times 3 \leq 86.7
\end{gathered}
$$

Where

$\mathrm{X} 1$ is no of loss buses

$\mathrm{X} 2$ is p.u.volts that atributes to the power losses in the distribution network.

$\mathrm{X} 3$ is distributed power losses (mw) in these buses $\mathrm{P}$ is percentage of loss in the distribution network

Figure 2. Optimized Genetic Algorithm Technique.

\subsection{Improving Loss Minimization in 33kv Power Distribution Network Using Optimized Genetic Algorithm}

$\%$ Minimize

$\% \mathrm{P}=3 \mathrm{X} 1+0.865 \mathrm{X} 2+150 \mathrm{X} 3$

$\% \mathrm{ST}$.

$\% 5 \mathrm{X} 1+0.76 \mathrm{X} 2+120 \mathrm{X} 3 \leq 80$

$\% 6 \times 1+0.835 \times 2+140 \times 3 \leq 76.7$

$\% 8 \mathrm{X} 1+0.784 \mathrm{X} 2+110 \mathrm{X} 3 \leq 81.7$

$\% 9 \mathrm{X} 1+0.763 \mathrm{X} 2+80 \mathrm{X} 3 \leq 86.7$

$\%$ Where

$\% \mathrm{X} 1$ is no of loss buses

$\% \mathrm{X} 2$ is p.u.volts that atributes to the power losses in the distribution network.

$\% \mathrm{X} 3$ is distributed power losses (mw) in these buses

$\% \mathrm{P}$ is percentage of loss in the distribution network

\% Chromosome ( X1, X2, X3, P)

$\mathrm{f}=\left[\begin{array}{lll}-3 & -0.865 & -150]\end{array}\right.$

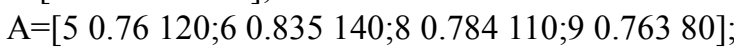

$\mathrm{b}=[80 ; 76.7 ; 81.7 ; 86.7]$;

Aeq $=\left[\begin{array}{lll}0 & 0 & 0\end{array}\right]$;

beq $=[0]$;

$\mathrm{LB}=\left[\begin{array}{lll}0 & 0 & 0\end{array}\right]$;

$\mathrm{UB}=[$ infinfinf $]$;

[X,FVAL,EXITFLAG] $=\operatorname{linprog}(\mathrm{f}, \mathrm{A}, \mathrm{b}, \mathrm{Aeq}, \mathrm{beq}, \mathrm{LB}, \mathrm{UB})$ Optimization terminated.

$\mathrm{X}=$

0.0000

0.0000

0.5479

$\mathrm{FVAL}=$

$-82.1786$

\section{EXITFLAG=}

1 
The distributed power loss is minimized to 0.5479 or 0.55

\subsection{To design a SIMULINK Model for Improving Loss Minimization in 33kv Power Distribution Network Using Optimized Genetic Algorithm}

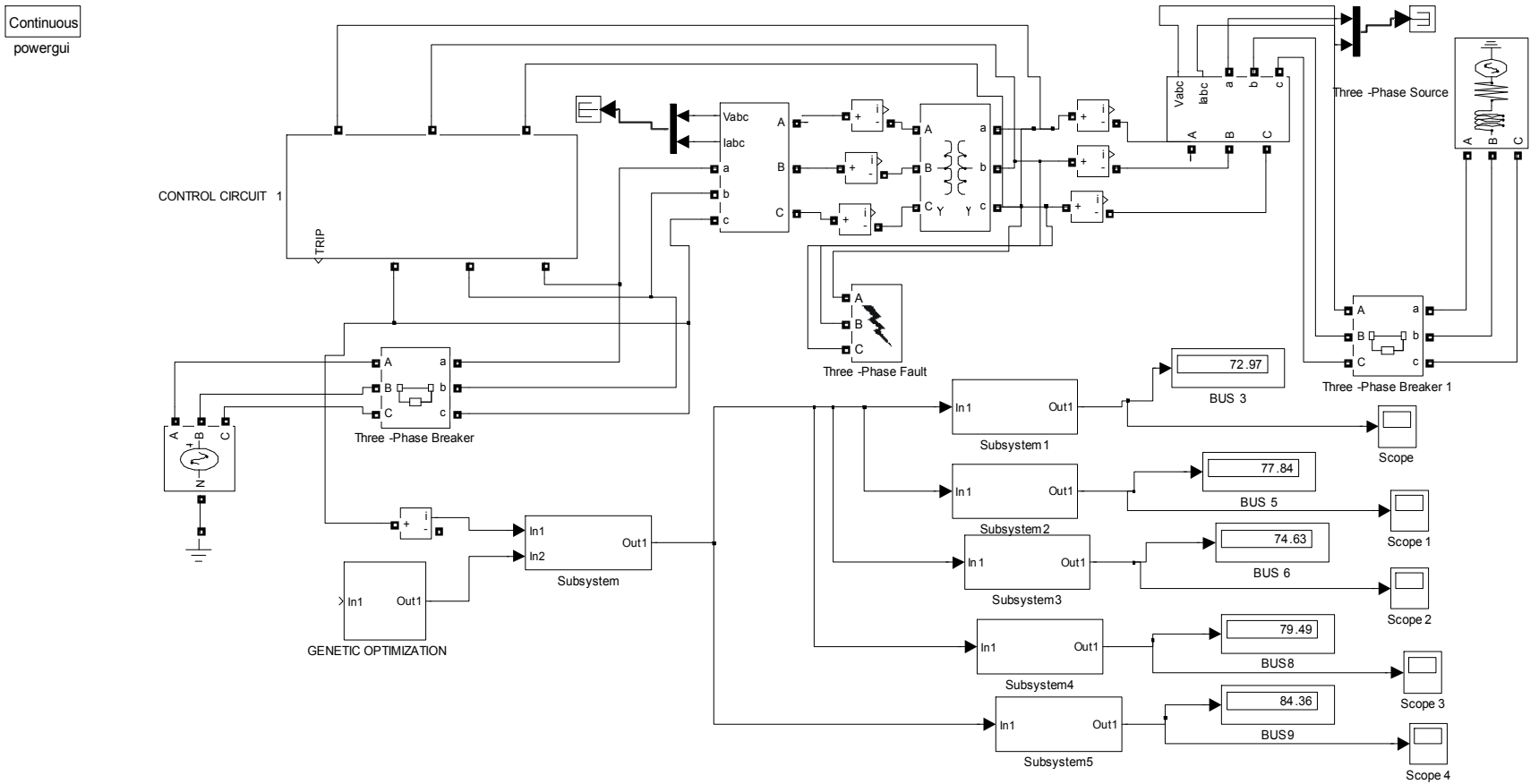

Figure 3. Designed SIMULINK model for improving loss minimization in 33kv power distribution network using optimized genetic algorithm.

\section{Results and Discussion}

Figure 1 is the Load flow analysis of the $33 \mathrm{kV}$ distribution network under consideration while Figure 2 shows the step by step technique of using Optimized Genetic Algorithm. Figure 3 depicts the designed SIMULINK model for improving loss minimization in $33 \mathrm{kv}$ power distribution network using optimized Genetic algorithm. Figure 4 is a comparison of percentage power loss in bus 3 of $33 \mathrm{KV}$ distribution network with and without Optimized genetic algorithm, Figure 5, Compares percentage power loss in bus 5 of $33 \mathrm{KV}$ distribution network with and without Optimized genetic algorithm Table 2 shows determined distribution losses.

The results obtained at different faulty buses in the distribution network shows that there is reduction in percentage of power losses in distribution network as detailed in figures 4 and Figure 5 respectively.
In figure 4 , the Percentage power loss in bus 3 of $33 \mathrm{kV}$ distribution network with and without Optimized Genetic Algorithm was compared, and the result presented here showed that the conventional percentage power loss in $33 \mathrm{KV}$ distribution network is $75 \%$ while that when optimized genetic algorithm is incorporated in the system is $72.9 \%$. With these results obtained, the percentage improvement in loss reduction in $33 \mathrm{KV}$ distribution network when optimized genetic algorithm is imbibed in the system is $2.1 \%$.

Figure 5 shows the comparison between percentage power loss in bus 5 of $33 \mathrm{KV}$ distribution network with and without Optimized genetic algorithm; the result presented revealed that the conventional percentage of power loss in $33 \mathrm{KV}$ distribution network is $80 \%$ while the percentage power loss in the distribution network when Optimized genetic algorithm is incorporated in the system is $72.9 \%$. This shows that there is power loss reduction in distribution network when optimized genetic algorithm is introduced in the system.

Table 3. Comparing percentage power loss in bus 3 of $33 \mathrm{KV}$ distribution network with and without Optimized genetic algorithm.

\begin{tabular}{lll}
\hline Time (s) & $\begin{array}{l}\text { Conventional power loss in bus3 of 33kv power } \\
\text { distribution network (\%) }\end{array}$ & $\begin{array}{l}\text { Optimized genetic algorithm power loss in bus3 of 33kv } \\
\text { power distribution network (\%) }\end{array}$ \\
\hline 0 & 75 & 72.9 \\
1 & 75 & 72.9 \\
2 & 75 & 72.9 \\
3 & 75 & 72.9 \\
4 & 75 & 72.9 \\
10 & 75 & 72.9 \\
\hline
\end{tabular}




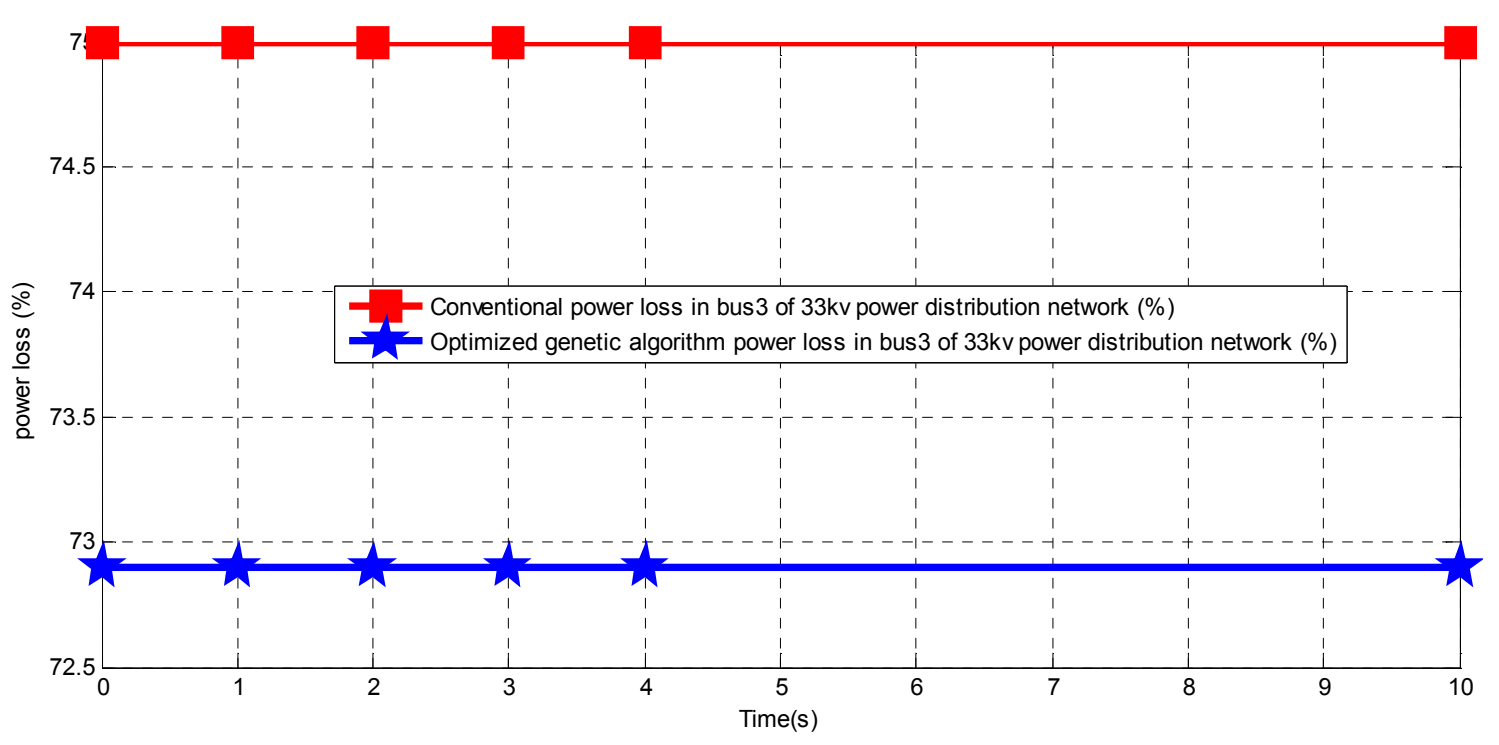

Figure 4. Comparing percentage power loss in bus 3 of $33 \mathrm{KV}$ distribution network with and without Optimized genetic algorithm.

Table 4. Comparing percentage power loss in bus 5 of $33 \mathrm{KV}$ distribution network with and without Optimized genetic algorithm.

\begin{tabular}{lll}
\hline Time (s) & $\begin{array}{l}\text { Conventional power loss in bus5 of 33kv power distribution } \\
\text { network (\%) }\end{array}$ & $\begin{array}{l}\text { Optimized genetic algorithm power loss in bus5 of 33kv } \\
\text { power distribution network (\%) }\end{array}$ \\
\hline 0 & 80 & 72.9 \\
1 & 80 & 72.9 \\
2 & 80 & 72.9 \\
3 & 80 & 72.9 \\
4 & 80 & 72.9 \\
10 & 80 & 72.9 \\
\hline
\end{tabular}

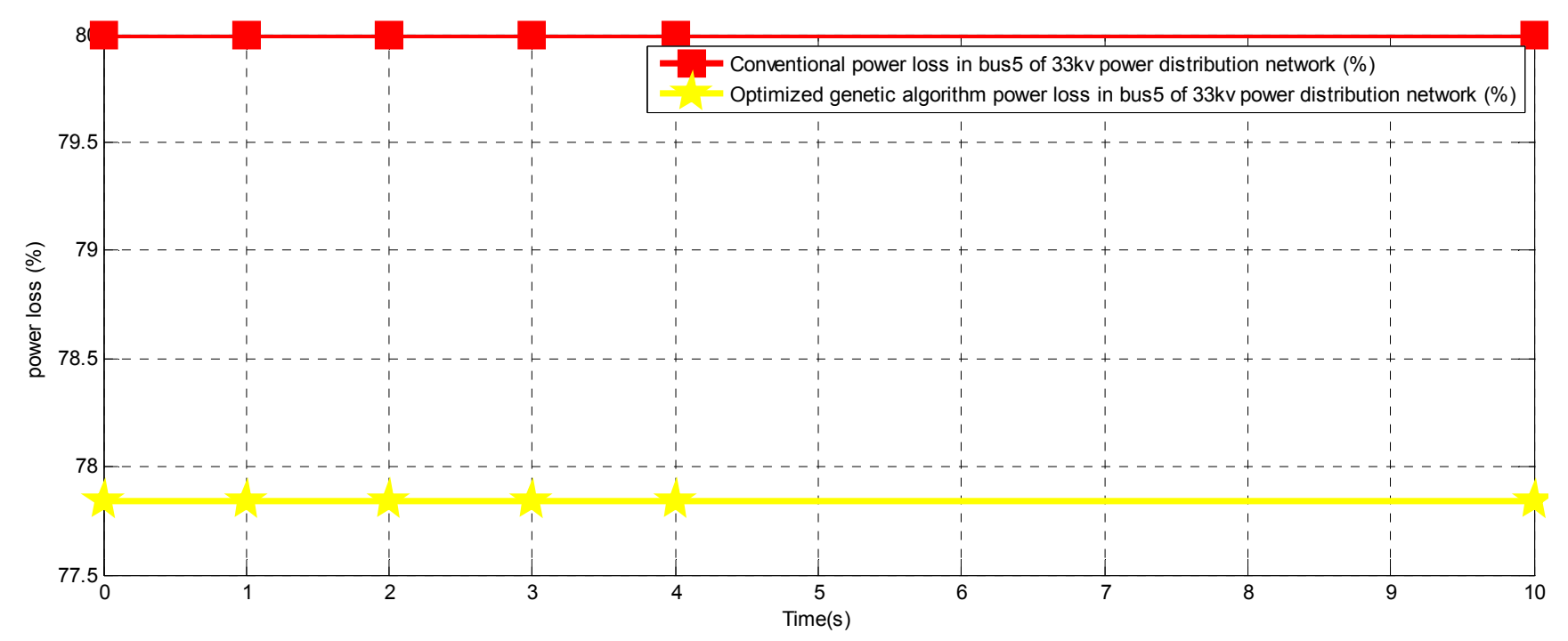

Figure 5. Comparing percentage power loss in bus 5 of $33 \mathrm{KV}$ distribution network with and without Optimized genetic algorithm.

\section{Conclusion and Recommendation}

The intermittent power supply in our distribution network has liquidated some establishment that solely depend on power to run their daily work. This is due to power loss in the distribution network. This irregular power supply in the distribution network is overcome by improving loss minimization in $33 \mathrm{kv}$ power distribution network using optimized genetic algorithm. It is done in this manner, characterizing $33 \mathrm{KV}$ distribution network, running the load flow of the characterized $33 \mathrm{KV}$ distribution network, determining the distribution losses from the load flow.

Minimizing the determined losses in $33 \mathrm{kv}$ distribution network using optimized genetic algorithms, and designing SIMULINK model for improving loss minimization in $33 \mathrm{kv}$ power distribution network using optimized genetic algorithm. Finally, validating and justifying the percentage of loss reduction in improving 
loss minimization in $33 \mathrm{kv}$ power distribution network without and with optimized genetic algorithm. The results obtained are conventional percentage power loss in $33 \mathrm{KV}$ distribution network is $75 \%$ while that when optimized genetic algorithm is incorporated in the system is $72.9 \%$. With these results obtained the percentage improvement in loss reduction in $33 \mathrm{KV}$ distribution network when optimized genetic algorithm is imbibed in the system is $2.1 \%$. The conventional percentage of power loss in $33 \mathrm{KV}$ distribution network is $80 \%$. On the other hand, the percentage power loss in the distribution network when Optimized genetic algorithm is incorporated in the system is $72.9 \%$. This shows that there is power loss reduction in distribution network when optimized genetic algorithm is incorporated in the system. The conventional power loss in distribution network is $76.7 \%$ while that when optimized genetic algorithm is inculcated in the system is $74.63 \%$. The conventional percentage power loss in distribution network in bus 8 is $81.7 \%$ while that when optimized genetic algorithm is imbibed in the system is $79.49 \%$. The conventional percentage power loss in bus 9 of $33 \mathrm{KV}$ distribution network is $86.7 \%$. Finally, when optimized genetic algorithm is incorporated in the system the percentage power loss in the distribution network reduced drastically to $84.36 \%$. With these results, it shows that the improvement in minimizing power loss in $33 \mathrm{KV}$ distribution network is $2.34 \%$.

\section{Recommendations}

To ensure optimum performance reliability of electricity supply in $33 \mathrm{kV}$ power distribution, the following recommendations are suggested based on the findings:

1. Losses could be minimized using Sychronous phase modifiers.

2. Capacitor banks should be placed in paralle to load centers to improve power factor.

3. Solid State var compensators should be encouraged in the distribution substations.

4. Preventive maintenance should be implemented quarterly to improve the integrity of power system components.

5. .4 Corona technical losses and non- technical losses could be minimize with timely replacement of dilapidated and old power system equipment. The Government should make provision for training technical personnel in the industry.

\section{Acknowledgements}

My thanks goes to the Faculty of Engineering, Enugu State University of Science and Technology for the use of resource materials necessary for the completion of this research work. This work is assisted by Ngatek Global Services Limited, a private company based in Cross River State, Nigeria whose corporate objective is to support and provide funds for research works.

\section{References}

[1] D. A. Bitew, A. O. Salau and Y. Gebru (2020).

[2] Load flow and contingency analysis for transmission line outage Arch. Electr. Eng., 69 (3), 273.

[3] A. E. B. Abu-Elanien and K. B. Shaban, (2018). Modern network reconfiguration techniques for service restoration in distribution systems: a step to a smarter grid. Alexandria Engineering Journal, 57 (4), pp. 3959-3967.

[4] Gerez, L. I. Silva and E. A. Belati (2019). Distribution network reconfiguration using selective firefly algorithm and a load flow analysis criterion for reducing the search space. IEEE Access, 7, pp. 67874-67888.

[5] Ade-Ikuesan, O. O., Okakwu, I. K. and Osifeko, M. O.,(2018). Investigation of electric power losses on primary distribution feeder: a case study of Sango - Ota distribution company, Ogun State, Nigeria. International Journal of Applied Engineering Research, Volume 13, Number 7, pp. 5000- 5003.

[6] M. Sedighizadeh, G. Shaghaghi-shahr and M. R. Aghamohammadi (2020) A new optimal operation framework for balanced micro grids considering reconfiguration and generation scheduling simultaneously.

[7] International Transactions on Electrical Energy Systems, pp. $1-31$.

[8] Juan Andrés Martín García, Antonio José Gil Mena (2013). "Optimal distributed generation location and size utilising a modified teaching-learning based optimization algorithm", Electrical Power and Energy Systems, vol 50, pp. 65-75.

[9] Aggelos S. Bouhouras, Kallisthenis I. (2016). "Optimal active and reactive nodal power requirements towards loss minimization under reverse power flow constraint defining DG type", Electrical Power and Energy Systems, vol 78, pp. 445-454.

[10] Mohammad H. and Moradi, S. M (2014). "Multi-objective PFDE algorithm for solving the optimal siting and sizing problem of multiple DG sources", Electrical Power and Energy Systems, vol 56, pp. 117-126.

[11] Kumar Mahesh, and Perumal N. (2016). "Advanced Pareto Front NonDominated Sorting Multi-Objective Particle Swarm Optimization for Optimal Placement and Sizing of Distributed Generation", Energies, 9, 982, pp. 2-23.

[12] N. Mohandas, R. and Balamurugan, L. (2015). "Optimal location and sizing of real power DG units to improve the voltage stability in the distribution system utilizing $\mathrm{ABC}$ algorithm united with chaos", Electrical Power and Energy Systems, vol. 66, pp. 41-52.

[13] Xiangang Peng, and Lixiang Lin (2015)."Crisscross Optimization Algorithm and Monte Carlo Simulation for Solving Optimal Distributed Generation Allocation Problem", Energies, 8, pp. 13641-13659.

[14] Zeng Pin-zhuo, Wang Ke-you, and Li Guo-jie (2017) "Optimization of Distributed Generation Integrated into Micro Grids Considering the Correlation of DGs", International Journal of Grid Distribution Computing, vol 8, no. 6, pp. 105116. International Journal of Grid and Distributed Computing Vol. 10, No. 5. 
[15] Duong Quoc Hung, and Nadarajah (2013). "Multiple Distributed Generator Placement in Primary Distribution Networks for Loss Reduction", IEEE Transactions on Industrial Electronics, vol. 60, no. 4, pp. 1700-1708.

[16] Komail, N., Malihe M. and Farsangi (2013) "An Improved Multi-Objective Harmony Search for Optimal Placement of DGs in Distribution Systems", IEEE Transactions on Smart Grid, vol. 4, no. 1, pp. 557-567.

[17] Qasim K. and, Xiangning, Lin (2016). "Optimal Placement and Capacity of Capacitor Bank in Radial Distribution
System", International Conference on Energy Efficient Technologies for Sustainability (ICEETS) pp. 416-423.

[18] G. Carpinelli, F. and Mottola (2010). "Optimal Allocation of Dispersed Generators, Capacitors and Distributed Energy Storage Systems in Distribution Networks", Modern Electric Power Systems (2010), pp. 1-6.

[19] Mohsin S. and Ishtiaq Ahmad (2016). "Load Concentration Factor Based Analytical Method for Optimal Placement of Multiple Distribution Generators for Loss Minimization and Voltage Profile Improvement", Energies, 9, 287, pp. 1-21. 